\title{
Thermo-structural Analysis of Coolant Channel Configurations of Actively Cooled Panels
}

\author{
Siva Karthik C V S S ${ }^{1, a}$, T Kishen Kumar Reddy ${ }^{1, b}$, Santhosh Kumar ${ }^{1, c}$ \\ ${ }^{1}$ Mechanical Engineering Department, Jawaharlal Nehru Technological University, \\ Hyderabad, India - 500085 \\ asseva.karthik@gmail.com, ${ }^{b}$ reddykishen@jntu.ac.in, ${ }^{\mathrm{c}}$ sknagula1991@gmail.com
}

\begin{abstract}
Keywords: Active cooling, Channel configuration, High speed combustion chambers, High temperature materials, Thermo-structural
\end{abstract}

\begin{abstract}
The liner of a high speed combustion chamber is subjected to high thermo-mechanical loads. Active cooling of the high speed combustor liner by using hydro carbon fuel is seen as a viable option due to its weight efficiency. But choice of the channel configuration has to be optimum. Two channels shape viz., rectangular and trapezoidal are investigated and compared. The purpose of this paper is to bring out most suitable shape of the channel which can withstand the thermo-mechanical loads. During the investigation, various high temperature materials are studied for their suitability for this application. Apart from thermo-mechanical loads, the configurations are constrained to have minimum weight per unit area, which is important for aero-space applications. The study brings out the most efficient material cum configuration suitable for application to the high speed combustion chamber for the given heat flux. In the initial study, various configurations are verified based on minimum weight per unit area with the help of 1D MATLAB program and the results are further validated by performing 2D thermo-structural analysis using ANSYS. It was found that $\mathrm{Nb}-\mathrm{Cb} 752$ can serve at lower mass flow rates when compared to Inconel X-750. GRCop-84 is not suitable for the given heat flux and coolant flow rates. In terms of weight per unit areas, $\mathrm{Nb}-\mathrm{Cb} 752$ has high weight per unit area at lower coolant mass flow rates of up to $0.0065 \mathrm{~kg} / \mathrm{m}^{2}$ and subsequently reduces and remains constant with increase in the mass flow rate from 0.0065 to $0.009 \mathrm{Kg} / \mathrm{m}^{2}$. Inconel is found to have higher weight per unit area than $\mathrm{Nb}-\mathrm{Cb} 752$ at a given mass flow rate. Between rectangular and Trapezoidal, latter is found to have slightly lower weight per unit area for all the materials considered.
\end{abstract}

\section{Introduction}

The combustion liners have to be cooled effectively to withstand the high thermal loads from the combustion gases for the entire duration of operation. The liner must also withstand the thermo-mechanical stress arising due to high temperature gradients and pressure prevailing inside the combustion chamber. The weight constraint rules out the use of tradition cooling options and active cooling is seen as a viable alternative. Active cooling has been an area of active research currently in many countries. In active cooling, the fuel is used as coolant. It is passed through a channel inside the liner to participate in the heat exchange. The main objective is to arrive at active cooling configuration that has minimum weight per unit area and can withstand the thermo-mechanical loads. Here the weight includes the weight of the panel and the coolant combined. Many proposals have been made, to arrive at a suitable configuration which can effectively cool the high heat fluxes encountered during the combustion.

Valdevit et al. [1] have shown that the geometry of the coolant channel, the thermo-physical properties of the coolant, material of the combustor and the conditions prevailing in the combustion chamber all influence the heat transfer rates. Parametric studies of rectangular channels were performed, for a range of geometric parameters, heat transfer coefficients. Thermal Barrier Coatings (TBCs) were also found to be beneficial to increase the feasibility of the actively cooled panel. Young et al. [3] optimized the cooling panel satisfying hydrodynamic, thermal and Mach number constraints. 
The purpose of the present paper explores the effect of the shape of the channel on thermal and structural performance of an active cooling panel. Various materials were employed to come up with a suitable material cum configuration which is suitable for this application. For the investigation 1-D heat transfer MATLAB program was developed considering walls of the channel as fin with insulated tip. Two types of fins are considered for writing the program, viz., rectangular and trapezoidal. The approach for writing this program is similar to that of Valdevit et al [1]. With the help of this program thermo-structural performance is evaluated for combination of various shapes and materials to arrive at the optimal dimensions of the channel for minimum coolant flow rate and minimum weight per unit area. Once the optimal material and shape configurations are selected, 2D thermo-structural analysis is performed using ANSYS to validate the results.

\section{Overview of 1D MATLAB program}

The 1D MATLAB evaluates the temperatures based on the fin analogy with the boundary condition that one end of the fin is insulated. One side of the channel is exposed to high temperature gases, while other sides are assumed to be insulated. MATLAB program calculates the amount of the coolant mass flow required, to maintain structural integrity for the given coolant pressure inside the coolant channel, the pressure of the combustion gases and temperature gradients. The constraints being metal temperature should not exceed the material usage temperature, the temperature of the coolant should not exceed coking limit of the fuel and the Von-Mises stresses are to be within the yield limit of the given material. The thermal resistance network shown in the Fig. 1 is considered for obtaining the temperatures of the material due to heat flux from the combustion gases. The temperatures and stresses are evaluated at 18 critical points as shown in the Fig. 2. Three different high temperature materials listed in Table 1 are investigated for their suitability. Their properties are taken from the literature.

Table 1. Material Properties.

\begin{tabular}{|c|c|c|c|c|c|c|c|}
\hline Material & $\begin{array}{c}\text { Usage } \\
\text { Temperat } \\
\text { ure }(K)\end{array}$ & $\begin{array}{c}\text { Density } \\
(\mathrm{Kg} / \mathrm{m3})\end{array}$ & $\begin{array}{c}\text { Coefficient } \\
\text { of thermal } \\
\text { expansion } \\
\left(10^{-6} / \mathrm{K}\right)\end{array}$ & $\begin{array}{c}\text { Coefficient } \\
\text { of thermal } \\
\text { conductivity } \\
\left(\mathrm{W} / \mathrm{m}^{2} \mathrm{~K}\right)\end{array}$ & $\begin{array}{c}\text { Yield } \\
\text { Stress } \\
(\mathrm{MPa})\end{array}$ & $\begin{array}{c}\frac{d \sigma}{d T} \\
(\mathrm{MPa} / \mathrm{K})\end{array}$ & $\begin{array}{c}\text { Young's } \\
\text { Modulus } \\
(\mathrm{GPa})\end{array}$ \\
\hline GRCop-84 & 973 & 8756 & 19 & 285 & 205 & -0.18 & 90 \\
\hline Nb-Cb752 & 1470 & 9030 & 7.4 & 50 & 382 & -0.39 & 110 \\
\hline Inconel X-750 & 1100 & 8276 & 16 & 23 & 527 & -0.17 & 128 \\
\hline
\end{tabular}

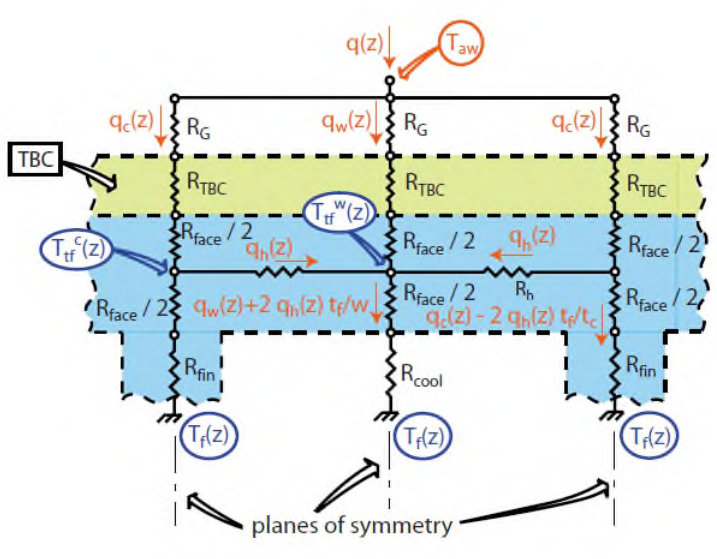

The convective and conductive thermal resistances are given below:

$R G=\frac{1}{h G}$

Rface $=\frac{t f}{K s}$

$R h=\frac{(w+t c / 2)}{4 K s}$

Rcool $=\frac{1}{h c}$

Rfin $=$ Resistance of fin is based on the shape of the fin from [6] are given in Table 2

$\mathrm{R}_{\mathrm{TBC}}=$ Resistance due to the thermal barrier coating is not considered for the current investigation.

Fig. 1 Thermal resistance network used for evaluation of temperatures.

(Courtesy: Valdevit et al. [1]) 
In order to incorporate the different shapes of the channel in to the program, following two changes were made to the original program. (I) Instead of mass flow rate per unit width, directly mass flow rate of the coolant is provided as an input. (II) The thermal resistances of rectangular and trapezoidal fin shapes are incorporated as given in Karthik et al. [2]. The length of the panel is taken as $0.7 \mathrm{~m}$. The inputs required are the realistic adiabatic wall temperature (Taw), wall temperature on the combustion side (Tw), heat transfer coefficient on combustion side ( $\mathrm{GG}$ ), coolant mass flow rate (mf), inlet temperature of the coolant (Ti) as encountered in experimental test conditions.

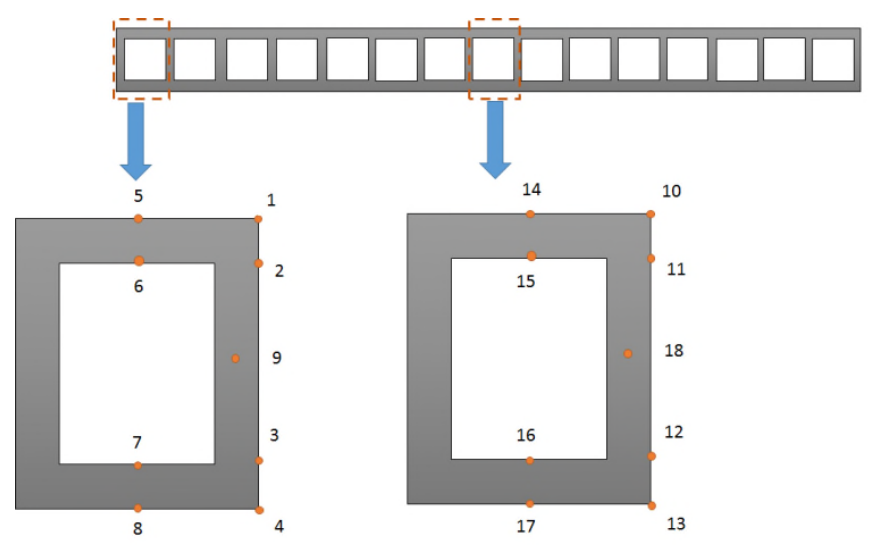

Fig. 2 Critical points identified on the panel for evaluating the stresses and temperature.

The hydrocarbon fuel JP-7 is used as a coolant throughout this investigation. Fig. 3 shows the flow chart for MATLAB program. Due to the incorporation of the rectangular and trapezoidal fins two different channel configurations are obtained as shown in Fig. 4.

Temperatures of the Channel. The heat transfer coefficient on the combustion side ' $h_{G}$ ' is calculated using Eckert's Reference Enthalpy method [7]. The conditions considered on the combustion chamber side are that of prevailing in the actual scenario. On the coolant side the inlet temperature is $300 \mathrm{~K}$.

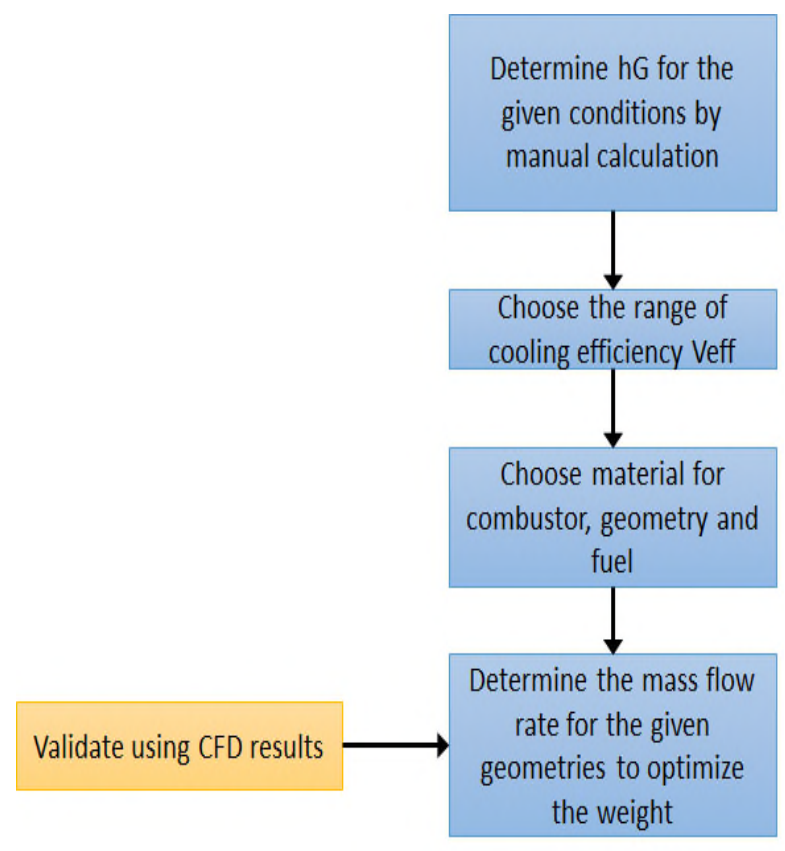

Fig. 3 Flow chart of 1-D Matlab program 


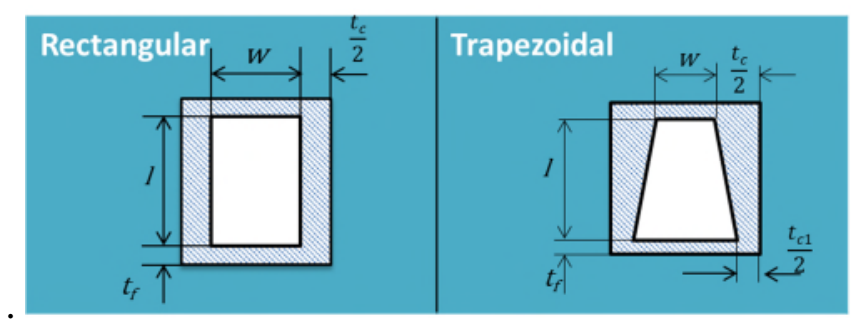

Fig. 4 Different channel shapes used in the investigation.

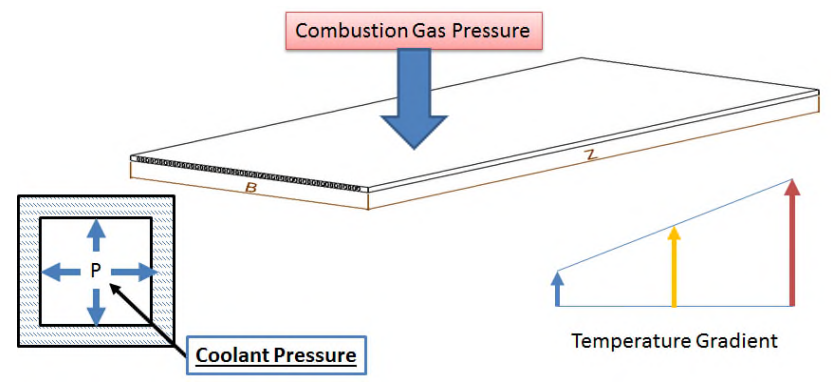

Fig. 5 Combustor panel.

The heat transfer coefficient inside the coolant channel is obtained from the Gnielinski correlation.

$$
h_{c}=\frac{k_{f}}{D_{h}} \mathrm{~N}_{\mathrm{u}}=\frac{k_{f}}{D_{h}} \frac{(f / 2)(\mathrm{Re}-1000) \operatorname{Pr}}{1+12.7 \sqrt{f / 2}\left(\operatorname{Pr}^{2 / 3}-1\right)}
$$

where, $\operatorname{Pr}$ is Prandtl number, Re is Reynolds number, $\mathrm{K}_{\mathrm{f}}-$ Thermal Conductivity of fluid, $\mathrm{D}_{\mathrm{h}}-$ Hydraulic Diameter, $\mathrm{f}$ - friction factor \& $\mathrm{Nu}$ - Nusselt Number

$\operatorname{Re}=\frac{u D_{h}}{v_{f}}$ where, $\mathrm{u}-$ velocity of the fluid in the pipe

$\mathrm{D}_{\mathrm{h}}=\frac{4 A}{P}$ where, $\mathrm{A}-$ Area, $\mathrm{P}$ - Perimeter

Friction factor $=f=\left(0.079 \ln (\mathrm{Re})^{-1.64}\right)^{-2}$

The thermal resistance network along with the heat transfer coefficients are used to find the temperatures at 18 critical points on the channel. The temperatures at the 18 points of a rectangular channel and fuel temperature were obtained as explained in the reference of Valdevit et al [1]. The temperatures of the trapezoidal channel were obtained in Karthik et al. [2]

Thermo-mechanical Stresses. Mechanical stresses are due to the pressure of the coolant inside the channel and the pressure due to combustion gases. The pressure inside the channel is considered uniformly throughout at $3 \mathrm{MPa}$ without assuming pressure drop. This assumption was made as the pressure drop for the channel length considered here is very minimal. Thermal stresses are due to temperature gradient across the channel. Both thermal and mechanical stresses are also evaluated at 18 critical points on the channel. The thermo-mechanical stresses for the rectangular channel are similar to that of Valdevit et al. [1], while the stresses in the trapezoidal channel were presented in Karthik et al. [2]. The suitable configuration is subject to constraints of metal temperature, coking limit temperature of fuel and Von-Mises stress criterion for the given mass flow rate.

The Matlab results are obtained for a range of values based on the manufacturing constraints. The channel width ' $\mathrm{w}$ ' is varied from $0.00125 \mathrm{~m}$ to $0.0035 \mathrm{~m}$, core thickness ' $\mathrm{t}$ ' ' is varied from $0.00125 \mathrm{~m}$ to $0.0025 \mathrm{~m}$. The rest of the geometric parameters such as face thickness ' $\mathrm{t}_{\mathrm{f}}$ ', flow channel height ' $\mathrm{l}$ ' are maintained at $0.0015 \mathrm{~m}$ and $0.005 \mathrm{~m}$ respectively. For Trapezoidal cross-section, the simulations are made for $\mathrm{t}_{\mathrm{c} 1}=\mathrm{t}_{\mathrm{c}}-0.0005$. The coolant flow rate is varied between $0.001 \mathrm{Kg} / \mathrm{s}$ to $0.01 \mathrm{Kg} / \mathrm{s}$.

This results in a list of suitable configurations for both Rectangular and Trapezoidal channels for all the materials considered. Then the minimum weight per unit area is identified for a given mass flow rate. The weight corresponds to the combined weight of the channel and fuel. The consideration 
of the weight of fuel is made since, the fuel weight adds up to the significant weight penalty. Hence the analysis is carried out by considering both the weight of the fuel and the metal. The section below describes the method used for calculating weight per unit area in this paper. Considering a panel width ' $B$ ' and length ' $Z$ ' as shown in the Fig. 5 and the width of the each channel is $b=w+t_{c}$ Number of channels for the given width of the panel are $\mathrm{N}=\mathrm{B} / \mathrm{b}$. The number will be rounded off to the nearest integer. Then metal volume of the panel is calculated. The weight of the panel $\left(\mathrm{W}_{\text {Panel }}\right)$ is volume times the density. The weight of the fuel $\left(\mathrm{W}_{\text {fuel }}\right)$ is the fuel required for the given duration of operation, say' $t$ ' seconds. Then the total weight of the fuel required is mass flow rate times the duration. The two quantities $\mathrm{W}_{\text {Panel }}$ and $\mathrm{W}_{\text {fuel }}$ are summed up to obtain the total weight $\left(\mathrm{W}_{\text {total }}\right)$. The surface area is calculated by the product of B and $\mathrm{Z}$. Weight per unit area is obtained by dividing the total weight by the surface area $=\mathrm{W}_{\text {total }} /\left(\mathrm{B}^{*} \mathrm{Z}\right)$.

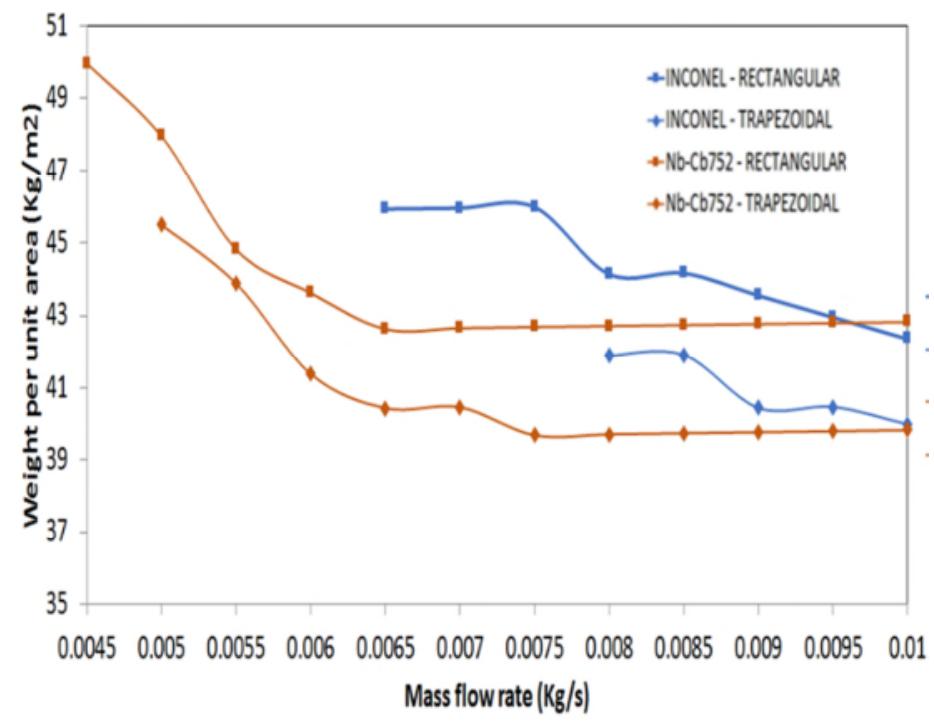

Fig. 6 Minimum weight per unit area for different mass flow rates for rectangular and trapezoidal sections.

MATLAB Results. The graph in Fig. 6 shows the comparative analysis of the minimum weight per unit area of different material and channel shapes combinations.

- The acceptable configuration in case of $\mathrm{Nb}-\mathrm{Cb} 752$ has started at a mass flow rate of $0.0045 \mathrm{Kg} / \mathrm{s}$ with a weight per unit area of $50 \mathrm{Kg} / \mathrm{m}^{2}$.

- The acceptable configuration for Inconel X-750 started at mass flow rate of $0.0065 \mathrm{Kg} / \mathrm{Sec}$ with weight per unit area of 46 , which is higher when compared to $\mathrm{Nb}-\mathrm{Cb} 752$ at 42.5 . This implies that for $\mathrm{Nb}-\mathrm{Cb} 752$ lower flow rates are sufficient to keep the temperature and stresses within the material temperature and yield stress limits.

- GRCop-84 could not withstand the given thermo-mechanical loads and hence does not appear in the graph.

-The weight per unit area for Inconel X-750 is higher than $\mathrm{Nb}-\mathrm{Cb} 752$ initially and reduced as the flow rate increased.

-In terms of configurations, rectangular is slightly heavier when compared to trapezoidal configurations for both $\mathrm{Nb}-\mathrm{Cb} 752$ and Inconel X-750.

- The trend observed is similar to the graph from Valdevit et al. [1] shown in Fig. 7, which provides the comparison for minimum weight unit area for different materials for rectangular configuration for a given heat transfer coefficient and adiabatic wall temperature. The difference is that graph in Fig. 7 gives the minimum weight per unit area considering weight of the metal, but in Fig. 6 both weight of the metal and fuel are considered. While making a choice based on the weight per unit area, that coolant flowing can significantly add up to overall weight.

-The configuration is a yield based design. Von-Mises stress criterion is used for arriving at 
suitable configurations.

- From the above it can be inferred that the $\mathrm{Nb}-\mathrm{Cb} 752$ with trapezoidal configuration at flow rate of $0.0075 \mathrm{Kg} / \mathrm{s}$ has the lowest weight per unit area of $39 \mathrm{Kg} / \mathrm{m}^{2}$ and hence more suitable for the application.

Though above discussion does not bring out the geometric parameters of the channel but it helps to compare the configurations and the materials for minimum weight at different mass flow rates.

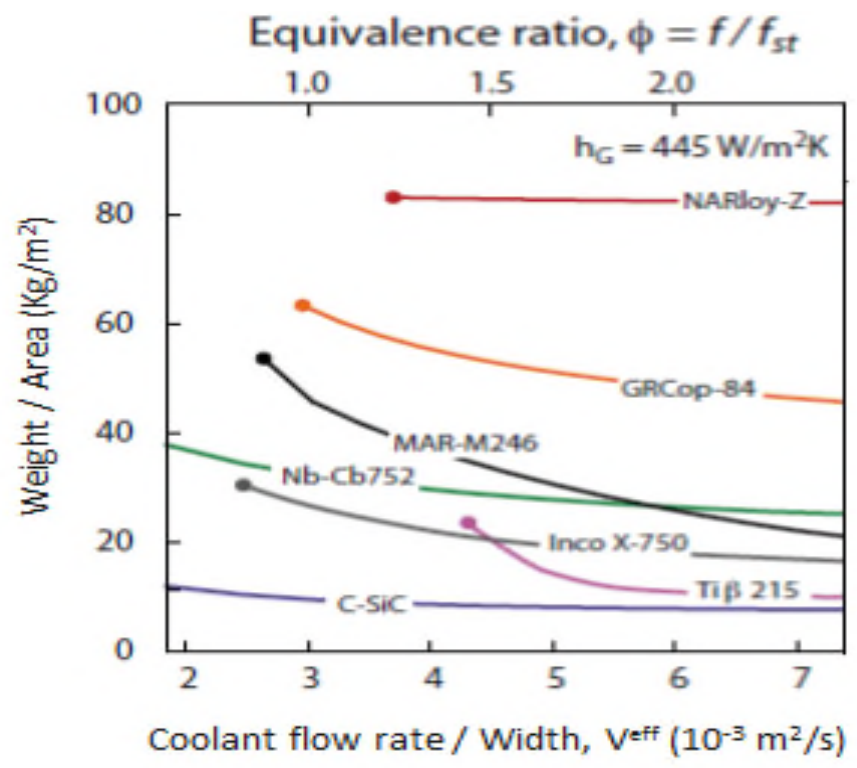

Fig. 7 Minimum Weight comparison at $\mathrm{h}_{\mathrm{G}}=445 \mathrm{~W} / \mathrm{m}^{2} \mathrm{~K}$. (Courtesy: Valdevit et al.[1])

\section{Thermo-structural Analysis}

In order to verify the results obtained above, 2D plane strain thermo-structural analysis is carried out in ANSYS. The analysis was carried out for both rectangular and trapezoidal configurations. The simulations are carried out for $\mathrm{Nb}-\mathrm{Cb} 752$ material only as it was found to be suitable at lower mass flow rates within the given manufacture feasible geometric parameters. The channel material is $\mathrm{NbCb}-752$

Boundary Conditions:

- Mechanical Loads: Pressure on the channel wall - $3 \mathrm{MPa}$

- Heat Transfer coefficient on the coolant side (derived from the Gnielinski Correlation)

- Temperature of the coolant (derived from the energy balance) and explained in Appendix

- Heat Transfer coefficient on the combustion side of the all (derived from Eckert's Enthalpy condition) $697.5 \mathrm{~W} / \mathrm{m}^{2} \mathrm{~K}$

- Adiabatic wall temperature $3297 \mathrm{~K}$

- The bottom portion is assumed to be on a bed rollers permitting expansion in all the directions. The panel level bending is restricted.

- The bottom wall is constrained against the movement in Y - Direction

- The left side wall is constrained against the movement in X-Direction

- In order to allow for the thermal expansion, the right side wall is allowed to displace uniformly in the X-direction

\section{Results \& Discussion}

Fig. 8, 9 shows the thermo-structural results obtained for rectangular and trapezoidal sections.

The results show that analytical and numerical models show good correlation at the top face of the channel where the temperatures are high. 
For both rectangular and trapezoidal configurations the stresses are evaluated at 18 critical points and along the profile of the channel.

In numerical analysis, the stress exceeded the yield limit at the corner due to stress concentration. These stresses are ignored for the current analysis, since these can be overcome by increasing the corner radius and also the plasticity of the material redistributes the stresses.

From the above analysis, it can be seen that the MATLAB can be used as a first approximation of the suitability of a given channel configuration and followed by ANSYS simulation to confirm the result. Following is the list of some of the configurations and their geometric parameters for each of the material. For a typical combustor, the number of channels is calculated. Overall weight per unit area is calculated considering the total metal weight for these channels and fuel weight flowing in all these channels for given duration of time. The Von-Mises criterion is also shown for reference.

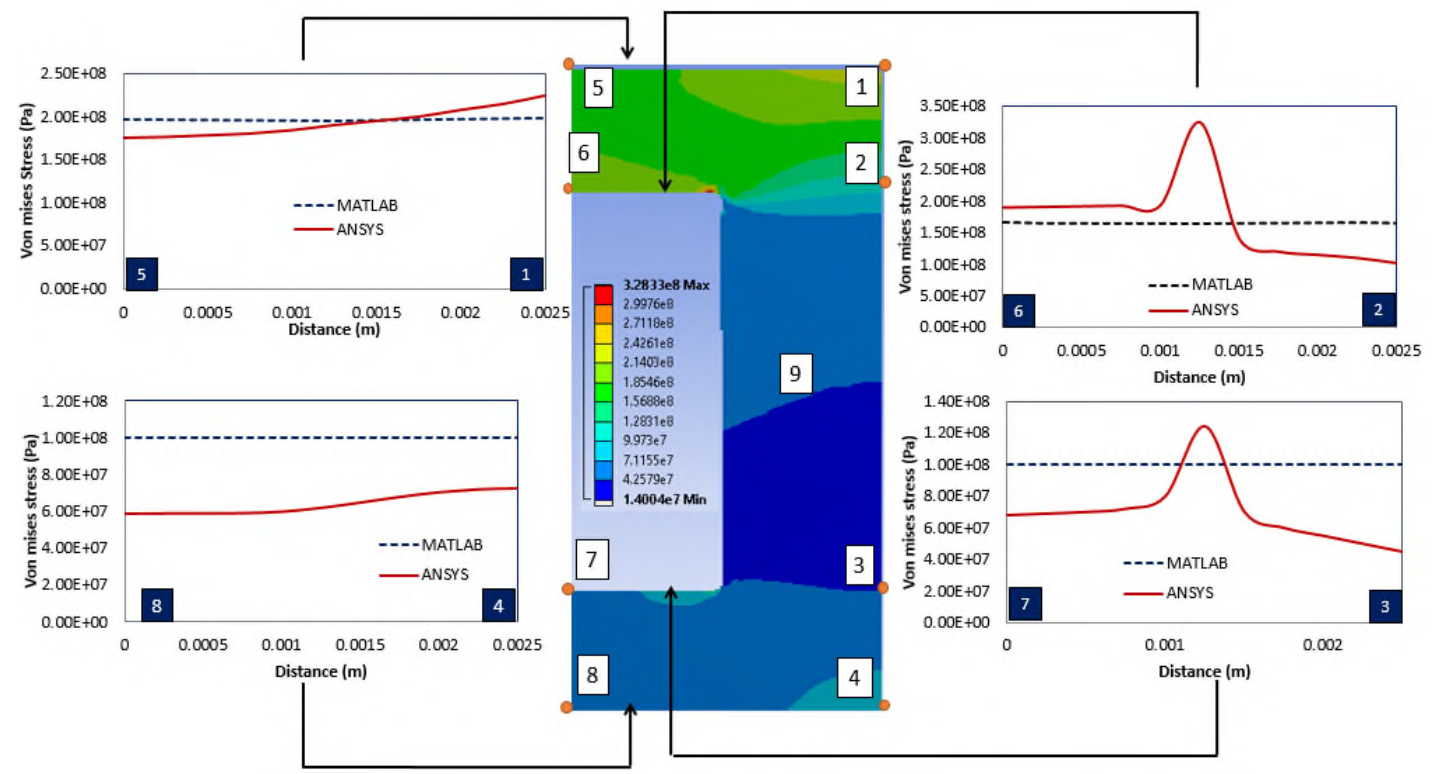

Fig. 8 Comparison of Von-Mises stresses between ANSYS and MATLAB.

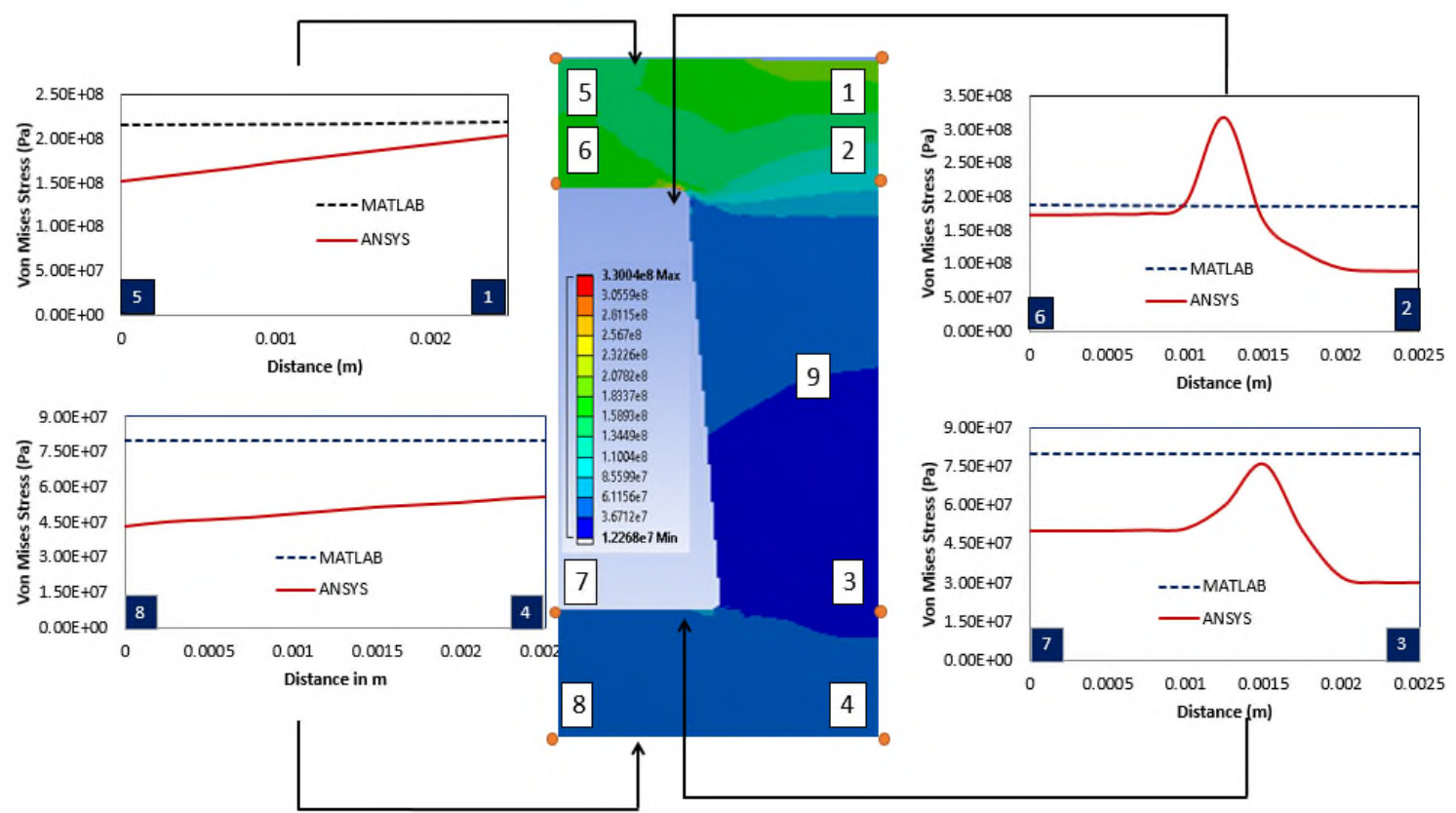

Fig. 9 Comparison of Von-Mises stresses between ANSYS and MATLAB. 
Table 2 (a). Inconel X-750 Rectangular \& Trapezoidal configurations.

\begin{tabular}{|c|c|c|c|c|c|c|c|c|c|c|c|c|c|c|c|}
\hline \multicolumn{16}{|c|}{ INCONEL X-750 - RECTANGULAR } \\
\hline $\begin{array}{c}\text { Mass flow } \\
\text { rate- } \mathbf{m}_{\mathrm{f}} \\
\mathbf{K g} / \mathbf{s})\end{array}$ & \multicolumn{2}{|c|}{$\begin{array}{l}\text { Weight per } \\
\text { unit area } \\
\left(\mathrm{Kg} / \mathrm{m}^{2}\right)\end{array}$} & \multicolumn{2}{|c|}{$\begin{array}{c}\text { Total wt. per } \\
\text { unit area } \\
\left(\mathrm{Kg} / \mathbf{m}^{2}\right)\end{array}$} & \multicolumn{2}{|c|}{$\begin{array}{l}\text { Width - } \\
\text { W (m) }\end{array}$} & $\begin{array}{l}\text { Height } \\
\text { - L (m) }\end{array}$ & \multicolumn{2}{|c|}{$\begin{array}{c}\text { Thickness } \\
\text { of the core } \\
-t_{c}(m)\end{array}$} & \multicolumn{2}{|c|}{$\begin{array}{c}\text { Channel } \\
\text { count - } \\
\text { N }\end{array}$} & \multicolumn{2}{|c|}{$\begin{array}{l}\mathrm{VMC} \\
\text { criterion } \\
<2\end{array}$} & \multicolumn{2}{|c|}{$\begin{array}{c}\text { Max. Von Mises } \\
\text { Stress- } \sigma \mathrm{VMC} \text { Max } \\
\left(\mathbf{N} / \mathbf{m}^{2}\right)\end{array}$} \\
\hline 0.0065 & \multicolumn{2}{|c|}{5.5716} & \multicolumn{2}{|c|}{45.9324} & \multicolumn{2}{|c|}{0.00125} & 0.005 & \multicolumn{2}{|c|}{0.00125} & \multicolumn{2}{|c|}{308} & \multicolumn{2}{|c|}{1.98} & \multicolumn{2}{|r|}{$5.25 \mathrm{E}+08$} \\
\hline 0.007 & \multicolumn{2}{|l|}{45.5716} & \multicolumn{2}{|c|}{45.9602} & \multicolumn{2}{|c|}{0.00125} & 0.005 & \multicolumn{2}{|c|}{0.00125} & \multicolumn{2}{|c|}{308} & \multicolumn{2}{|c|}{1.8} & & $11 \mathrm{E}+08$ \\
\hline 0.009 & \multicolumn{2}{|l|}{45.5716} & \multicolumn{2}{|c|}{46.0712} & \multicolumn{2}{|c|}{0.00125} & 0.005 & \multicolumn{2}{|c|}{0.00125} & \multicolumn{2}{|c|}{308} & \multicolumn{2}{|c|}{1.5} & \multicolumn{2}{|r|}{$4.67 \mathrm{E}+08$} \\
\hline 0.01 & \multicolumn{2}{|c|}{45.5716} & \multicolumn{2}{|c|}{46.1267} & \multicolumn{2}{|c|}{0.00125} & 0.005 & 0.00 & 0125 & & 08 & & .4 & & $4.51 \mathrm{E}+08$ \\
\hline & & & & II & 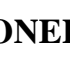 & $\mathbf{T}$ & $50 \quad T D$ & ADR & 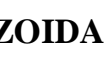 & & & & & & \\
\hline $\begin{array}{c}\text { Mass flow } \\
\text { rate- } \mathbf{~ m f} \\
\mathrm{Kg} / \mathrm{s})\end{array}$ & $\begin{array}{c}\text { Weight per } \\
\text { unit area } \\
\left(\mathrm{Kg} / \mathbf{m}^{2}\right)\end{array}$ & $\begin{array}{r}\text { Tota } \\
\text { un } \\
(\mathbf{K}\end{array}$ & $\begin{array}{l}\text { I wt. per } \\
\text { it area } \\
\left.\mathrm{g} / \mathrm{m}^{2}\right)\end{array}$ & $\begin{array}{l}\text { Widt } \\
\text { W (n }\end{array}$ & & $\begin{array}{r}\text { Height } \\
\text { L (m) }\end{array}$ & - $-\begin{array}{r}\text { Co } \\
\text { thick } \\
\text { at bot } \\
-t_{c 1}\end{array}$ & $\begin{array}{l}\text { re } \\
\text { ness } \\
\text { ttom } \\
\text { (m) }\end{array}$ & \begin{tabular}{|} 
Thickr \\
of th \\
core \\
$(\mathrm{m})$
\end{tabular} & $\begin{array}{l}\text { ness } \\
\text { he } \\
-\mathbf{t}_{\mathrm{c}} \\
\text { ) }\end{array}$ & $\begin{array}{l}\text { Chanr } \\
\text { count }\end{array}$ & & $\begin{array}{r}\text { VM } \\
\text { crite } \\
<2\end{array}$ & & $\begin{array}{c}\text { Max. Von } \\
\text { Mises Stress } \\
-\sigma \mathrm{VMCmax} \\
\quad\left(\mathbf{N} / \mathbf{m}^{2}\right)\end{array}$ \\
\hline 0.0076 & 41.4443 & & .8662 & 0.000 & & 0.00125 & 0.0 & & 0.001 & & 308 & & 1.980 & 021 & $5.24 \mathrm{E}+08$ \\
\hline 0.008 & 47.1528 & & .5969 & 0.001 & & 0.00125 & 0.0 & & 0.002 & 200 & 237 & & 1.941 & 116 & $5.19 \mathrm{E}+08$ \\
\hline 0.01 & 49.7257 & & .2808 & 0.002 & & 0.00125 & 0.0 & & 0.002 & & 205 & & 1.717 & & $4.88 \mathrm{E}+08$ \\
\hline
\end{tabular}

Table 2 (b). Nb-Cb752 Rectangular \& Trapezoidal configurations.

\begin{tabular}{|c|c|c|c|c|c|c|c|c|c|c|c|c|c|}
\hline \multicolumn{14}{|c|}{ Nb-Cb 752 - RECTANGULAR } \\
\hline $\begin{array}{c}\text { Mass flow } \\
\text { rate- } \mathbf{m}_{\mathrm{f}} \\
\mathbf{K g} / \mathbf{s})\end{array}$ & $\begin{array}{l}\text { Weight per } \\
\text { unit area } \\
\left(\mathrm{Kg} / \mathrm{m}^{2}\right)\end{array}$ & \begin{tabular}{|c|c|} 
per & Total \\
wt. per \\
ea & unit \\
)$^{2}$ & area \\
& $\left(\mathrm{Kg} / \mathbf{m}^{2}\right)$ \\
\end{tabular} & \multicolumn{2}{|c|}{ Width - W (m) } & $\begin{array}{l}\text { Height } \\
\text { - L (m) }\end{array}$ & \multicolumn{2}{|c|}{$\begin{array}{c}\text { Thickness } \\
\text { of the core } \\
-t_{c}(m)\end{array}$} & \multicolumn{2}{|c|}{$\begin{array}{c}\text { Channel } \\
\text { count - } \\
\text { N }\end{array}$} & \multicolumn{2}{|c|}{$\begin{array}{c}\mathrm{VMC} \\
\text { criterion } \\
<2\end{array}$} & \multicolumn{2}{|c|}{$\begin{array}{c}\text { Max. Von Mises } \\
\text { Stress- } \sigma \text { VMCmax } \\
\left(\mathbf{N} / \mathbf{m}^{2}\right)\end{array}$} \\
\hline 0.0045 & 49.7235 & 49.9733 & \multicolumn{2}{|c|}{0.00125} & 0.005 & \multicolumn{2}{|c|}{0.00125} & \multicolumn{2}{|c|}{308} & \multicolumn{2}{|c|}{1.21638} & & $2.05 \mathrm{E}+08$ \\
\hline 0.005 & 49.7235 & 50.0011 & \multicolumn{2}{|c|}{0.00125} & 0.005 & \multicolumn{2}{|c|}{0.00125} & \multicolumn{2}{|c|}{308} & \multicolumn{2}{|c|}{1.08023} & & $1.93 \mathrm{E}+08$ \\
\hline 0.006 & 54.914 & 55.2471 & \multicolumn{2}{|c|}{0.00125} & 0.005 & \multicolumn{2}{|c|}{0.00200} & \multicolumn{2}{|c|}{237} & \multicolumn{2}{|c|}{0.856684} & & $1.72 \mathrm{E}+08$ \\
\hline 0.01 & 57.2534 & 57.8085 & \multicolumn{2}{|c|}{0.00125} & 0.005 & \multicolumn{2}{|c|}{0.00250} & & 05 & \multicolumn{2}{|c|}{0.532635} & & $1.36 \mathrm{E}+08$ \\
\hline \multicolumn{14}{|c|}{ Nb-Cb 752 - TRAPEZOIDAL } \\
\hline $\begin{array}{c}\text { Mass flow } \\
\text { rate- } \mathbf{m}_{\mathrm{f}} \\
\mathrm{Kg} / \mathbf{s})\end{array}$ & $\begin{array}{c}\text { Weight per } \\
\text { unit area } \\
\left(\mathrm{Kg} / \mathrm{m}^{2}\right)\end{array}$ & $\begin{array}{c}\text { Total wt. per } \\
\text { unit area } \\
\left(\mathrm{Kg} / \mathrm{m}^{2}\right)\end{array}$ & $\begin{array}{l}\text { Width - } \\
\text { W (m) }\end{array}$ & $\begin{array}{r}\text { Heigh } \\
\text { L (m }\end{array}$ & t - $\begin{array}{r}\text { Co } \\
\text { thick } \\
\text { at bo } \\
-t_{c} 1\end{array}$ & $\begin{array}{l}\text { re } \\
\text { sness } \\
\text { otom } \\
\text { (m) }\end{array}$ & $\begin{array}{r}\text { Thickn } \\
\text { of the } \\
\text { core - } \\
\text { (m) }\end{array}$ & $\begin{array}{c}\text { ness } \\
\text { ne } \\
-t_{c}\end{array}$ & $\begin{array}{l}\text { Chan } \\
\text { count }\end{array}$ & & $\begin{array}{r}\mathrm{VM} \\
\text { crite } \\
<2\end{array}$ & $\begin{array}{l}\mathrm{IC} \\
\text { rion } \\
2\end{array}$ & $\begin{array}{c}\text { Max. Von } \\
\text { Mises Stress } \\
-\sigma \text { VMCmax } \\
\left(\mathbf{N} / \mathbf{m}^{2}\right)\end{array}$ \\
\hline 0.0048 & 45.220 & 45.486 & 0.00125 & 0.005 & 0.00 & 075 & 0.0012 & & 308 & & 1.3 & & $2.15 \mathrm{E}+08$ \\
\hline 0.005 & 45.220 & 45.497 & 0.00125 & 0.005 & 0.00 & 075 & 0.0012 & & 308 & & 1.2 & & $2.10 \mathrm{E}+08$ \\
\hline 0.006 & 47.676 & 48.009 & 0.00125 & 0.005 & 0.0 & 01 & 0.0015 & & 280 & & 1.0 & & $1.89 \mathrm{E}+08$ \\
\hline 0.006 & 43.582 & 43.915 & 0.0015 & 0.005 & 0.00 & 075 & 0.0012 & & 280 & & 1.2 & & $2.09 \mathrm{E}+08$ \\
\hline 0.01 & 39.26 & 39.68 & 0.0025 & 0.005 & 0.00 & 0075 & 0.0012 & & 205 & & 1.7 & & $2.45 \mathrm{E}+08$ \\
\hline
\end{tabular}

\section{Conclusions}

From the above analysis, it can be seen that the ANSYS \& MATLAB show good correlation.

- $\mathrm{Nb}-\mathrm{Cb} 752$ material is found to withstand the heat loads with lower coolant flow rates of as low as $0.0045 \mathrm{Kg} / \mathrm{s}$ when compared to Inconel X-750 which starts at $0.0065 \mathrm{Kg} / \mathrm{s}$. Thus the coolant flow rate requirement for Inconel X-750 is 1.4 times higher.

-GRCop - 84 material is not suitable for the given thermo-mechanical loads and flow rates.

-In terms of weight, trapezoidal was found to be advantageous when compared to rectangular 
configuration. The weight of trapezoidal configuration was observed to be $5 \%$ lower than rectangular for any of the materials considered and at any given flow rate. This could be due to the thinner cross sections of the trapezoidal channels being effective in heat exchange and withstand the stresses.

- The number of channels influences the weight of the panel, which in turn depends on the dimensions of the channel. In two configurations highlighted in the table $2 \mathrm{~b}$ above, for $\mathrm{Nb}-\mathrm{Cb} 752$ material and trapezoidal configuration, the number of channels and mass flow rate are same, but the weight per unit area showed a difference of $9 \%$. From this it can be inferred that the choice of the coolant channel configuration has to be made considering the overall weight per unit area of both panels and fuel, thermal load and coolant availability.

\section{References}

[1] V. Lorenzo, V. Natasha, W. Z. Frank, G. E. Anthony, A materials selection protocol for light weight actively cooled panels, J. Appl. Mech. 75(6) (2008) 061022-1 - 061022-15.

[2] C. V. S. S. Siva Karthik, N. Santhosh Kumar, T. Kishen Kumar Reddy, Effect of TBC on the performance of the active cooling channel, Int. J. Sci. Eng. R. 6(9) (2015) 1593-1601.

[3] B. Youn, A. F. Millst, Cooling Panel Optimization for the Active Cooling System of a Hypersonic Aircraft, J. thermophysic. Heat Transf. 9(1) (1995) 136-143.

[4] www.specialmetals.com INCONEL® alloy X-750 (UNS N07750/W. Nr. 2.4669)

[5] L. E. David, GRCop-84: A High-Temperature Copper Alloy for High-Heat-Flux Applications, NASA/TM-2005-213566, 2005.

[6] P. Frank. Incropera, P. D. W. David, Heat and Mass Transfer, Fifth edition, W. John \& Sons, Inc. 141

[7] D. Q. Robert, G. Leslie, Real time aerodynamic heating and surface temperature calculation for hypersonic flight simulations, NASA technical memorandum, 4222, 1990.

[8] M. P. Tresa, T. Sammy, Nickel-Based Superalloys for Advanced Turbine Engines: Chemistry, Microstructure, and Properties, J. propulsion power, 22(2) (2006) 361-374. 